\title{
CONSEQUÊNCIAS AMBIENTAIS E GEOGRÁFICAS DA ALTERAÇÃO NO CURSO DO RIO COMPRIDO, IGUAPE, SP ${ }^{1}$
}

\section{GEOGRAPHICAL AND ENVIRONMENTAL CONSEQUENCES OF THE CHANGE IN THE COURSE OF THE COMPRIDO RIVER, IGUAPE, SP}

\author{
Claudio de MOURA ${ }^{2,4}$; Manoel Messias dos SANTOS $^{3}$; \\ Luiz Carlos LIBORIO²; Gláucia Cortez Ramos de PAULA²
}

\begin{abstract}
RESUMO - O rio Comprido ou Una do Prelado é um dos maiores e importantes rios da região da Juréia e até meados da década de 1950 era a principal via de acesso para escoar a produção agrícola até o Porto do Una, situado junto à sua foz. Em 1955, visando encurtar o percurso e reduzir o tempo de viagem, foi aberto um furado, ou seja, em um canal construído entre duas voltas do rio. Tal intervenção transformou parte do continente em uma ilha artificial, a Ilha do Ameixal, provocando erosão e o assoreamento do curso d'água, inviabilizando, em poucos anos, a navegação de embarcações de maior porte, impedindo o escoamento da produção local e dificultando o desenvolvimento econômico da região. Com base em pesquisa documental, cartográfica e histórica da região estudada este trabalho identifica e apresenta as consequências ambientais causadas pelas intervenções antrópicas: o alargamento do canal-do-furado causado pela erosão ao longo dos últimos 60 anos, que continua provocando erosão de suas margens por solapamento causando a degradação da vegetação de restinga; a criação de uma unidade de conservação da categoria Área de Relevante Interesse Ecológico - ARIE em uma ilha artificial. Identificamos, como consequência geográfica, que tal alteração causou a redução territorial cartográfica do município de Iguape em cerca de 400 ha, pois o limite municipal entre Iguape e Peruíbe, que era o curso natural do rio Comprido, devido à abertura do canal-do-furado passou a ser registrado nos mapas oficiais como sendo através do canal artificial aberto no passado.
\end{abstract}

Palavras-chave: implicações ambientais; Ilha Fluvial Artificial do Ameixal; rio Una do Prelado; Juréia.

\begin{abstract}
The Comprido or Una do Prelado River is one of the largest and most important rivers in the region of Juréia, it was the main access route to drain the agricultural production of the region to the port of Una until the mid-50, located near the mouth of the river. In 1955, aiming to shorten the route of the river and reduce travel time a "furado" was opened, in other words, a canal built between two laps of a river. Due to such intervention, part of the continent became an artificial island, "Ilha do Ameixal", causing erosion and silting up the watercourse, making impossible the navigation of larger vessels, in a few years, preventing the flow of local production and making difficult the economic development of the region. This work identifies and presents environmental consequences caused by anthropogenic interventions based on documentary research and the regions' historical cartographic study: the extending of "canal-do-furado" caused by erosion over the past 60 years, which keeps eroding its banks by washout and degrading the restinga vegetation; the creation of a conservation unit in the category of Relevant Ecological Interest Area - ARIE on an artificial island. As geographic consequence, we have identified that this change caused cartographic territorial reduction in Iguape municipality by approximately 400 ha, since the municipal boundary between Iguape and Peruíbe, which was the natural course of the Comprido River, is now recorded on official maps as through the open artificial canal in the past due to the opening of the "canal-do-furado".
\end{abstract}

Keywords: environmental implications; Artificial Fluvial Island of the Ameixal; Una do Prelado River; Juréia.

\footnotetext{
${ }^{1}$ Artigo científico. Recebido para análise em 22.01.2016. Aceito para publicação em 26.04.2016. Publicado on-line em 15.06.2016. IInstituto Florestal, Rua do Horto, 931, 02377-000 São Paulo, SP, Brasil.

${ }^{3}$ Fundação Florestal, Estrada do Guaraú, 4164, 11750-000 Peruíbe, SP, Brasil.

${ }^{4}$ Autor para correspondência: Claudio de Moura - claudio.moura@bol.com.br
} 


\section{INTRODUÇÃO}

O primeiro povoado estabelecido em Iguape ocorreu por volta de 1537 , no estuário do rio que deu origem ao seu nome (Iguape - ygya-pe, na língua tupi), devido ao predomínio de plantas aquáticas no rio denominadas aguapé Eichhornia sp. (Pontederiaceae) (Instituto do Patrimônio Histórico e Artístico Nacional - IPHAM, 2015; Instituto Brasileiro de Geografia e Estatística - IBGE, 2014c).

Situada em região litorânea, praticamente no sul das terras delimitadas pelo meridiano de Tordesilhas, tornou-se ponto de passagem de Portugueses, Castelhanos e Franceses nos primórdios do século XVI e reduto de aventureiros e exploradores em busca de riquezas em meados do século XVII. A descoberta do ouro de lavagem na região dos afluentes do rio Ribeira do Iguapé provocou o desenvolvimento da então, à época da fundação, Vila de Iguape (IBGE, 2014c).

No início do século XVIII, a maior parte das atividades mineradoras declinou e, em fins de 1700, o esmorecimento da exploração do ouro levou inclusive ao fechamento da oficina de fundição existente (IBGE, 2014c).

No final do século XVIII, o município de Iguape passou a ser um dos mais ricos da região do Vale do Ribeira e do Estado de São Paulo, em função da produção de arroz e outros produtos agrícolas, que exportava para Santos e Rio de Janeiro através de seu porto. Nessa época, não havia estradas na região e os rios eram as únicas vias de acesso e de escoamento da produção agrícola regional. Dessa maneira, o desenvolvimento econômico da região, que se baseava na produção agrícola, principalmente do arroz, dependia totalmente da manutenção dos cursos dos rios navegáveis para o transporte de mercadorias (Commissão Geographica e Geológica do Estado de São Paulo - CGG, 1920; Menezes, 1994; Valentin, 2003).

Para encurtar a distância até o Porto da Ribeira e, assim reduzir custos com o frete, entre 1827 e 1852 foi realizada a abertura do canal do Valo Grande (Valentin, 2003). Essa obra acelerou o processo erosivo, causando o assoreamento do rio Ribeira de Iguape e inviabilizando, no início do século XIX, o funcionamento do porto (GEOBRÁS, 1966; CGG, 1920).

Em 1914, a expedição "Exploração do Littoral da cidade de Santos à fronteira do Estado do Paraná", da Commissão Geographica e Geológica do Estado de São Paulo, já registrava que Iguape era uma "ilha artificial", formada após a abertura do canal do Valo Grande e que o rio Comprido ou Una do Prelado era um dos principais rios da região junto com o rio Ribeira de Iguape (CGG, 1920).

No município de Iguape, além da abertura do canal do Valo Grande, ocorreu também um outro fator de impacto na região. Em 1955, visando encurtar o percurso no rio Comprido ou Una do Prelado e reduzir o tempo de viagem para escoar a produção agrícola até o Porto do Una, foi aberto um furado, ou seja, um canal construído entre duas voltas do rio. Tal intervenção ajudou ainda mais na transformação de parte do continente em uma ilha artificial, a Ilha do Ameixal, provocando erosão das margens do canal e o assoreamento do curso d'água, inviabilizando, em poucos anos, a navegação de embarcações de maior porte, impedindo o escoamento da produção local e dificultando o desenvolvimento econômico da região.

Em 1985, a Ilha do Ameixal, com área aproximada de 400 ha, foi declarada Área de Relevante Interesse Ecológico - ARIE, visando proteger o ambiente natural por ela abrigado (Brasil, 1985). Essa categoria é uma Unidade de Conservação do grupo de Uso Sustentável, que tem como objetivo manter os ecossistemas naturais de importância regional ou local e regular o uso admissível dessas áreas, de modo a compatibilizá-lo com os objetivos de conservação da natureza (Brasil, 2004).

No ano de 1986, foi criada a Estação Ecológica Juréia-Itatins - EEJI com cerca de 80.000 ha, após uma longa luta de pesquisadores e ambientalistas junto aos governos estadual e federal (Nogueira-Neto, 2004). A EEJI é uma Unidade de Conservação de Proteção Integral que englobou totalmente a ARIE Ilha do Ameixal (São Paulo, 1986).

Em 2013, foi criado o Mosaico de Unidades de Conservação Juréia-Itatins, onde a área da Ilha do Ameixal, que antes integrava a E.E. Juréia-Itatins, passou a integrar a Reserva de Desenvolvimento Sustentável Barra do Una.

O objetivo deste trabalho foi levantar as alterações antrópicas ocorridas no curso natural do rio Comprido, na década de 1950, e as consequências ambientais e geográficas resultantes destas intervenções. 


\section{MATERIAL E MÉTODOS}

O município de Iguape está localizado na região do Vale do Ribeira e possui uma área de 197.796,70 hectares, que correspondem a 1.977,957 km² (IBGE, 2014a).

Atualmente, o município de Iguape é o maior em extensão territorial no Estado de São Paulo, porém, a região do Vale do Ribeira apresenta os menores Índices de Desenvolvimento Humano - IDH do estado (IBGE, 2014b).

$\mathrm{Na}$ rede hidrográfica da Estação Ecológica Juréia-Itatins os principais rios nascem nos domínios das serras e possuem sua principal área de drenagem nas planícies costeiras. Podem ser identificadas três principais bacias: rio Verde, rio Guaraú e rio Comprido, que é a mais extensa (Souza e Souza, 2004). $\mathrm{O}$ rio Comprido situa-se na Mesorregião do Litoral Sul do Estado de São Paulo, que é composta por 17 municípios, tanto da região da Baixada Santista quanto do Vale do Ribeira (IBGE, 2010).

O rio Comprido é um dos maiores cursos d'água da região do Vale do Ribeira com mais de 100 quilômetros de extensão (Por, 2004) e até meados da década de 1950 era a principal via de acesso para escoar a produção agrícola até o Porto do Una, situado junto à sua foz.

De acordo com a Divisão Geomorfológica do Estado de São Paulo, o rio Comprido ou Una do Prelado situa-se na Província Costeira na sub-região da Baixada Litorânea que é composta por sedimentos arenosos e/ou argilosos mais ou menos orgânicos, cuja origem está vinculada à história geológica do Quaternário tardio, ou seja, há cerca de 5.000 anos (Almeida apud Suguio, 2004).

A área denominada "Ilha do Ameixal" localiza-se nas proximidades da foz do rio Comprido ou Una do Prelado, município de Iguape, no Litoral Sul do Estado de São Paulo e ocupa uma área aproximada de 400 ha. Declarada como Área de Relevante Interesse Ecológico - ARIE em 1985, englobada pela Estação Ecológica Juréia-Itatins em 1986, passou a integrar a Reserva de Desenvolvimento Sustentável Barra do Una, com a criação do Mosaico de Unidades de Conservação Juréia-Itatins em 2013, conforme Figura 1 (São Paulo, 2013).

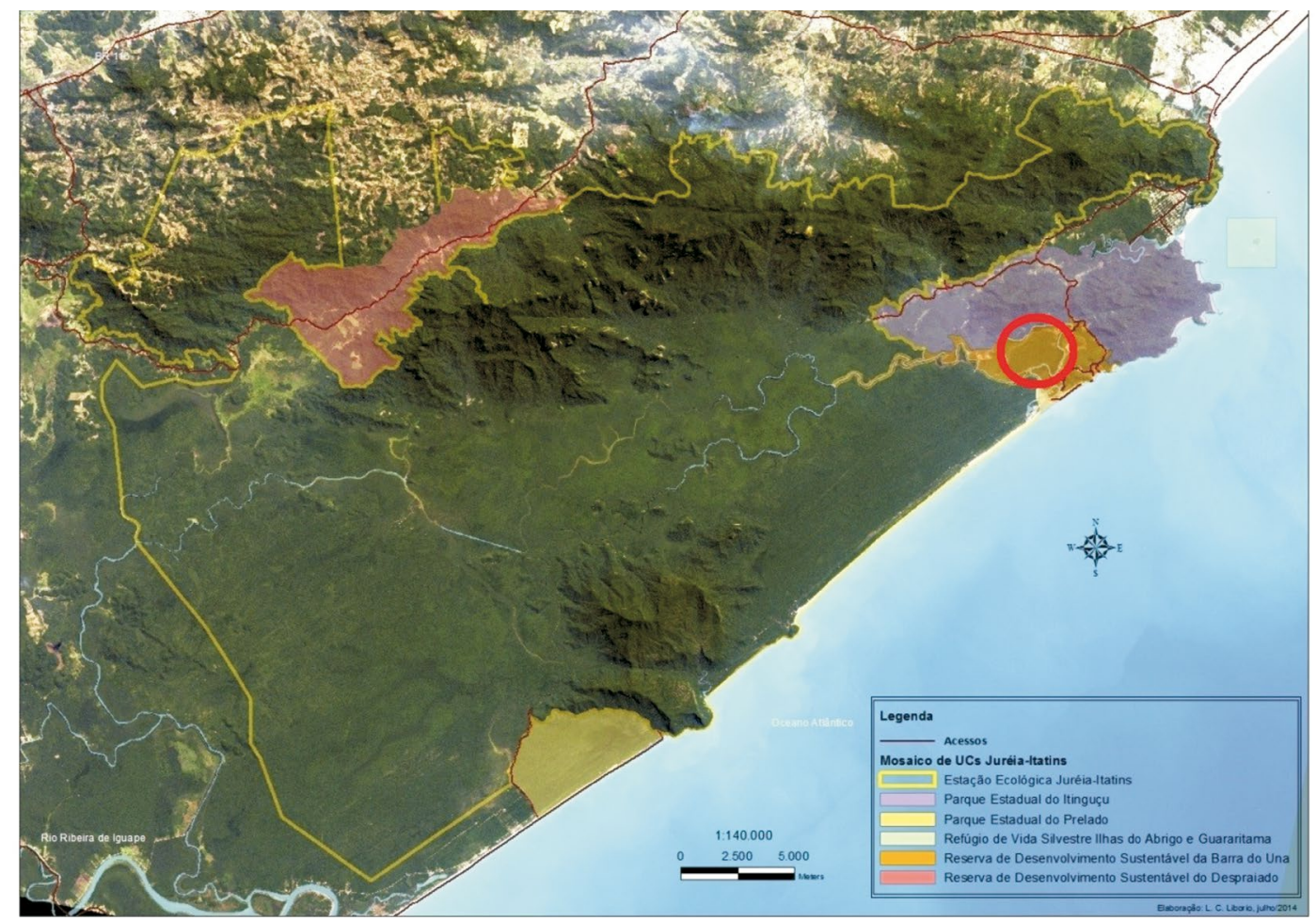

Figura 1. Mosaico de Unidades de Conservação Juréia-Itatins destacando a Reserva de Desenvolvimento Sustentável Barra do Una e Ilha do Ameixal.

Figure 1. Mosaic of Juréia-Itatins Protected Areas highlighting the Barra do Una Sustainable Development Reserve and "Ilha do Ameixal'. 
Com base em pesquisa documental, legislação ambiental, consulta à literatura específica sobre o tema, relatórios técnicos, mapas, cartas topográficas, fotografias aéreas, além da obtenção de informações junto às comunidades de moradores tradicionais da Praia do Una e da Vila Barra do Una, este trabalho levantou as alterações antrópicas ocorridas no curso natural do rio Comprido na década de 1950 e as consequências ambientais e geográficas resultantes destas intervenções.

Analisa também a criação de uma unidade de conservação da categoria Área de Relevante Interesse Ecológico - ARIE em uma ilha artificial.

Para a realização do estudo, foram utilizados os seguintes documentos: a) mapa em escala 1:50.000 da Commissão Geographica e Geológica - CGG, de 1914; b) carta topográfica em escala 1:50.000 do Instituto Geográfico e Cartográfico - IGC, de 1973; c) imagem do Satélite Alos do Instituto Nacional de Pesquisas Espaciais - INPE, de 2008; d) imagem de satélite do serviço de mapa Google Earth, de 06/10/2015. Para a elaboração dos mapas, utilizou-se o Sistema de Informações Geográficas, através do programa ArcGIS.

\section{RESULTADOS E DISCUSSÃO}

No mapa intitulado "Planta do Littoral do Estado e São Paulo - entre a Barra do Ribeira de Iguape e o Guarahú", elaborado pela Commissão Geographica e Geológica, em 1914 (CGG, 1920), a área denominada atualmente como "Ilha do Ameixal" fazia parte da porção continental da Praia do Una (Figura 2).

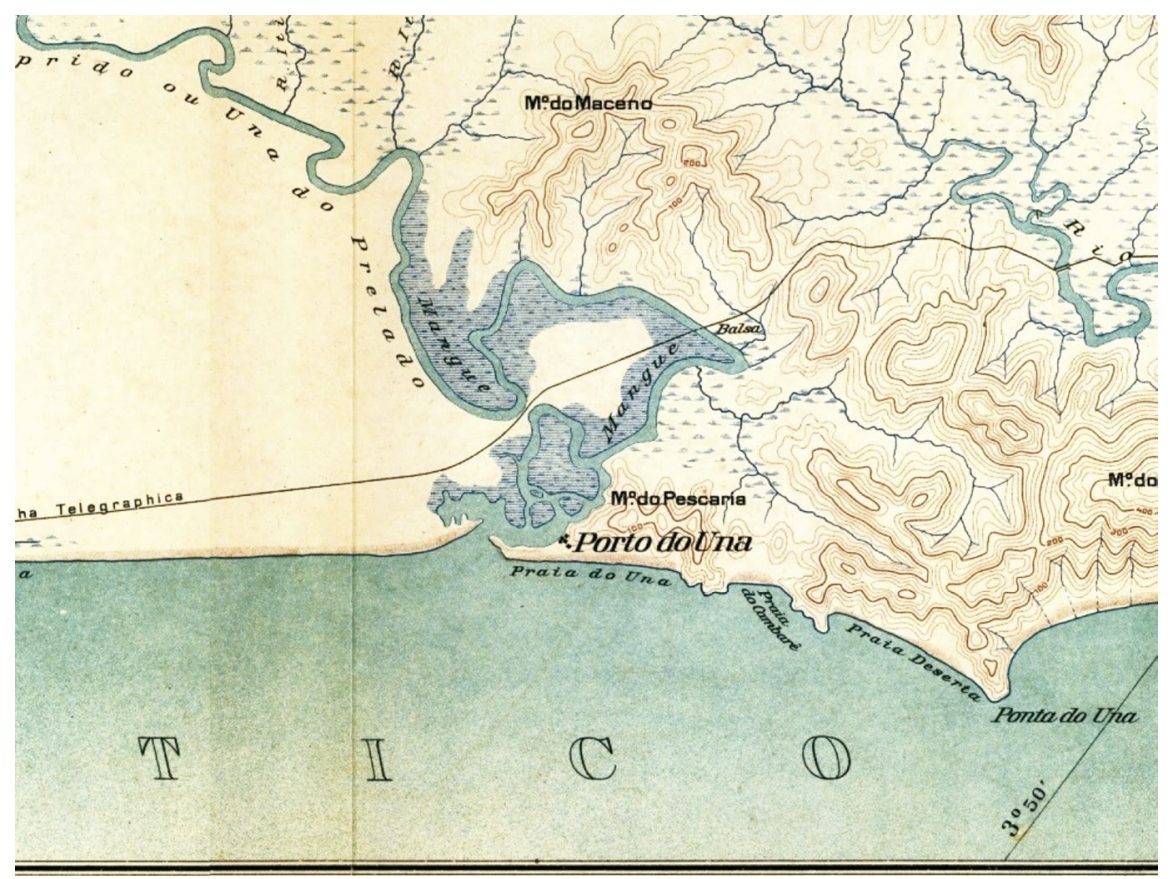

Figura 2. Região da foz do rio Una do Prelado em 1914 (CGG, 1920).

Figure 2. The region of the mouth of the Una do Prelado River in 1914 (CGG, 1920).

Segundo relatado por moradores tradicionais da região, o canal-do-furado do rio Una do Prelado foi aberto por volta de 1955, inicialmente com cinco metros de largura. Tal intervenção tinha o objetivo de encurtar o caminho entre a porção interior do rio e o Porto do Una, próximo à sua foz, diminuindo assim o custo e o tempo de viagem (Menezes, 1994).

O termo furado é empregado pelos moradores tradicionais da região, assim como em outras regiões do Brasil, para designar o canal artificial construído para diminuir a distância entre duas voltas de um rio (Houaiss et al., 2002).

Menezes (1994) cita o canal-do-furado do rio Una do Prelado, como uma das três intervenções antrópicas que afetaram o ecossistema estuarino na região da Juréia. 
Tal interferência antrópica transformou parte do continente em uma ilha artificial, a "Ilha do Ameixal". Segundo Menezes (1994), a abertura de um canal no rio Una do Prelado era uma necessidade para o desenvolvimento regional, pois este canal encurtava em mais de 10 quilômetros o percurso do rio, eliminando a "Volta Morta", assim denominada pelos moradores.

Porém, ao contrário do que se esperava e assim como ocorreu com a abertura do "Valo Grande" na cidade de Iguape, tal intervenção favoreceu a ocorrência de erosão e, consequentemente, o assoreamento do rio Una do Prelado, inviabilizando, em poucos anos, a navegação de embarcações de maior porte, impedindo o escoamento da produção local e dificultando, dessa maneira, o desenvolvimento econômico da região.

Como no final do século XVIII não havia estradas na região, e os rios eram as únicas vias de acesso e de escoamento da produção agrícola regional, seu desenvolvimento e continuidade dependia totalmente da manutenção dos cursos dos rios navegáveis para o transporte de mercadorias (CGG, 1920; Menezes, 1994; Valentin, 2003). No entanto, as soluções encontradas na época para reduzir os custos de viagem e de transporte comprometeram o desenvolvimento de toda a região do Vale do Ribeira.

Analisando o mapa elaborado em 1914, as informações prestadas por moradores tradicionais locais, as cartas topográficas de 1973, as informações apresentadas por Menezes (1994), a imagem de satélite Alos de 2008 e a imagem do Google Earth de 06/10/2015, verifica-se que o canal-do-furado do rio Una do Prelado evoluiu no período de 60 anos, entre 1955 e 2015, de cinco para 385 metros de largura, ou seja, o canal alargou em média 6,42 metros por ano. Apenas nos últimos sete anos, o canal-do-furado alargou 120 metros (Tabela 1).

Tabela 1. Evolução da largura do canal-do-furado do rio Una do Prelado, EEJI, SP.

Table 1. Width evolution of the "canal-do-furado" of the Una do Prelado River, EEJI, SP.

\begin{tabular}{ccc}
\hline Ano & Largura $(\mathrm{m})$ & Fonte \\
\hline 1955 & 5 & Comunicação pessoal de moradores locais \\
1958 & 50 & Menezes (1994) \\
1973 & 125 & Instituto Geográfico e Cartográfico \\
2008 & 265 & Imagem de satélite - Alos/INPE \\
2015 & 385 & Imagem do Google Earth de 06/10/2015 \\
\hline
\end{tabular}

A Figura 3 mostra a imagem de satélite da "Ilha do Ameixal" ilustrando a situação do local, com $265 \mathrm{~m}$ de largura, no ano de 2008.

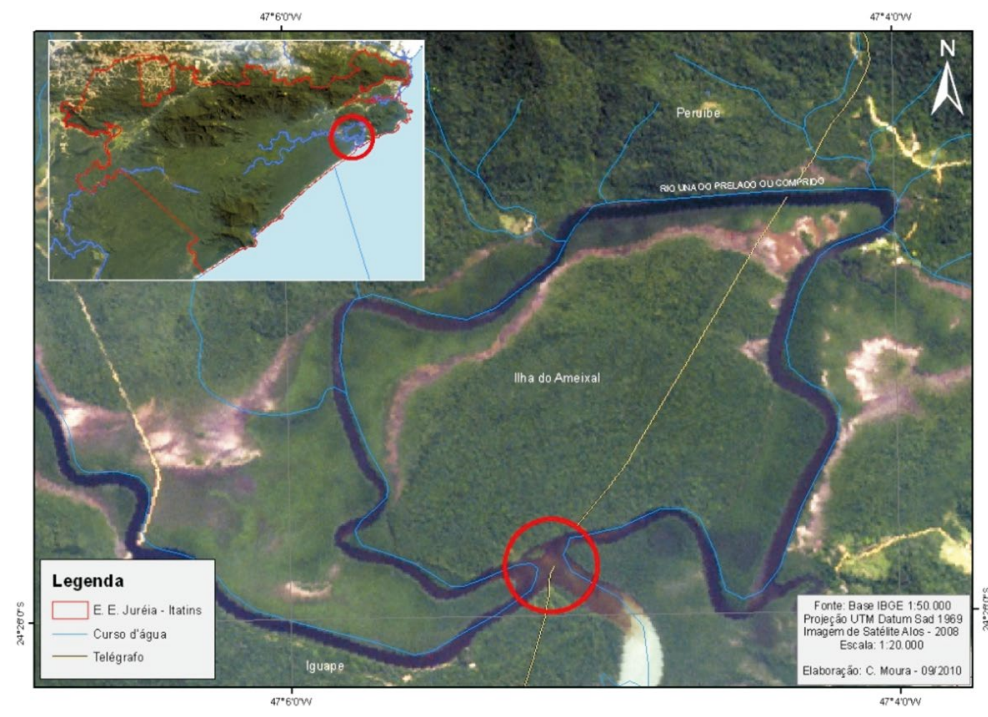

Figura 3. Imagem de satélite Alos da "Ilha do Ameixal" em 2008.

Figure 3. Alos satellite image of the "Ilha do Ameixal" in 2008. 
A Figura 4 mostra a Imagem do Google Earth da "Ilha do Ameixal" ilustrando a situação do local no ano de 2015, quando atingiu $385 \mathrm{~m}$ de largura.

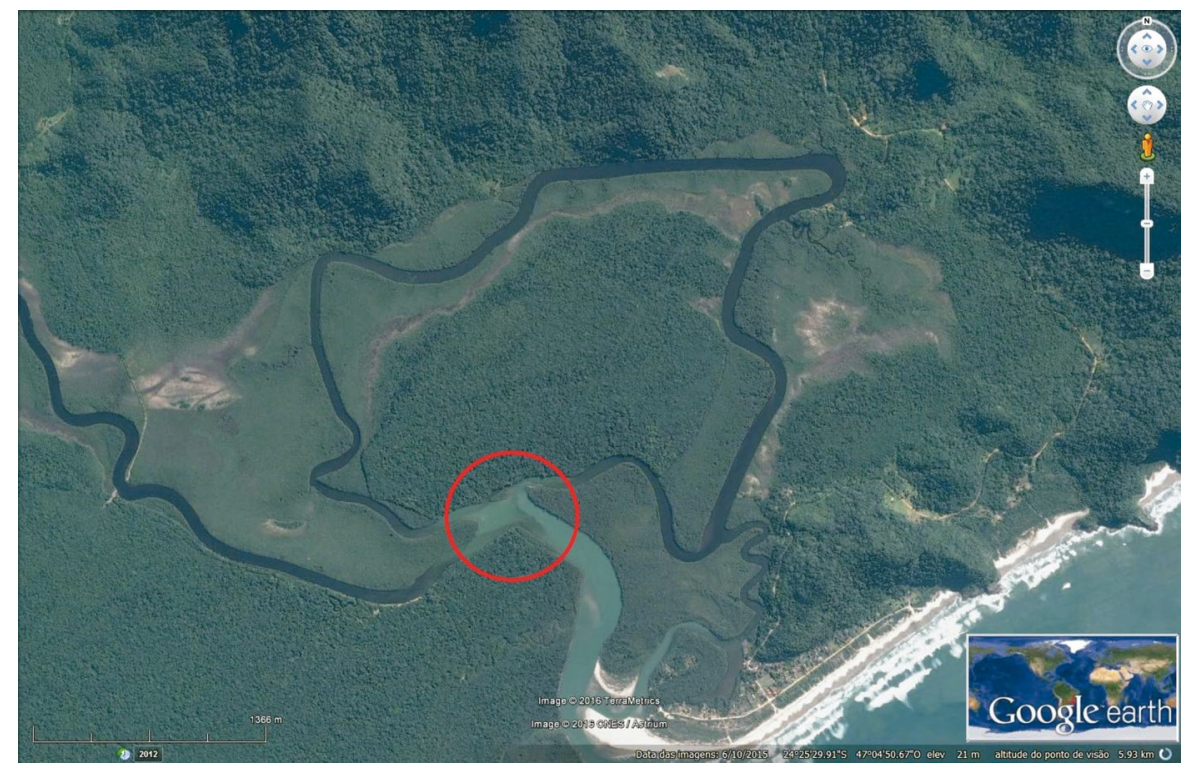

Figura 4. Imagem do Google Earth da "Ilha do Ameixal" em 2015.

Figure 4. Google Earth image of "Ilha do Ameixal" in 2015.

A areia carreada devido à abertura do canal-do-furado do rio Una do Prelado assoreou sua foz, mudando completamente a morfologia do estuário e impedindo a passagem dos barcos de maior porte pelo local e a navegação rio acima, alterando o desenvolvimento da região (Menezes, 1994).

Além das implicações ambientais e econômicas o canal-do-furado do rio Una do Prelado causou também problemas de ordem geográfica/cartográfica, pois neste trecho o rio é o limite entre os municípios de Iguape e Peruíbe, em seu curso original que seguia pela "Volta Morta". Como o canal-do-furado alterou seu traçado inclusive nas bases cartográficas do Instituto Brasileiro de Geografia e Estatística (IBGE, 2014a; IBGE, 2014c), verifica-se que a "Ilha do Ameixal", situada em Iguape, tem sido indicada erroneamente como pertencente ao município de Peruíbe, reduzindo, desta maneira, a extensão territorial do município de Iguape em cerca de 400 ha, área aproximada da ilha artificial do Ameixal.

Na década de 1980, técnicos da Secretaria Especial do Meio Ambiente - SEMA, órgão autônomo do Ministério do Desenvolvimento Urbano e Meio Ambiente do governo federal, propuseram que fosse criada nessa ilha, por eles denominada ilha fluvial do Ameixal, uma Área de Relevante Interesse Ecológico - ARIE, cuja criação foi efetivada pelo Decreto $\mathrm{n}^{0} 91.889$, de 5 de novembro de 1985 (Brasil, 1985). Esses técnicos provavelmente desconheciam que a referida ilha era artificial, formada a partir da alteração no curso do rio Una do Prelado.

$\mathrm{Na}$ época da criação da ARIE da Ilha do Ameixal, a legislação vigente estabelecia que para uma área ser declarada como ARIE deveria, preferencialmente, ter extensão inferior a 5.000 ha, possuir características naturais extraordinárias ou abrigar exemplares raros da biota regional, exigindo por parte do Poder Público cuidados especiais de proteção (Brasil, 1984).

A criação das Áreas de Relevante Interesse Ecológico - ARIEs era um dos instrumentos da Política Nacional do Meio Ambiente, cuja finalidade era manter os ecossistemas naturais, regional ou localmente importantes, além de regular o uso admissível dessas áreas, compatibilizando-o com os objetivos da conservação ambiental (Brasil, 1981). Porém, a edição do Sistema Nacional de Unidades de Conservação da Natureza - SNUC no ano 2000, revogou ou deu nova redação a vários de seus artigos, como o artigo $9^{\circ}$, inciso VI, e o artigo 18, da Lei $n^{\circ} 6.938$, de 31 de agosto de 1981, ambos relacionados com a criação de ARIEs. 
As normas que embasaram a criação das Áreas de Relevante Interesse Ecológico (Lei no 6.938/1981 e Decreto $\mathrm{n}^{\circ}$ 89.336/1984), na década de 1980, tinham a característica de proteção integral associada à possibilidade de uso compatível com a conservação ambiental. O Sistema Nacional de Unidades de Conservação da Natureza - SNUC manteve praticamente a mesma redação das legislações anteriores em relação à criação de ARIE, que tem como objetivo manter os ecossistemas naturais de importância regional (Brasil, 2004), porém, incluiu esta categoria no grupo de Unidades de Conservação de Uso Sustentável.

Então, de certo modo, a criação da ARIE da Ilha do Ameixal, no passado, cumpriu essa parte do objetivo, já que no local existem grandes extensões de Floresta de Restinga e manguezais, com toda a biodiversidade peculiar destes ecossistemas, porém, não considerou a origem histórica do local. Atualmente, com a criação do Mosaico de Unidades de Conservação Juréia-Itatins, em 2013, a área da Ilha do Ameixal passou a integrar a Reserva de Desenvolvimento Sustentável Barra do Una, cujo objetivo básico é de preservar a natureza e, ao mesmo tempo, assegurar as condições e os meios necessários para a reprodução e a melhoria dos modos e da qualidade de vida e exploração dos recursos naturais das populações tradicionais (Brasil, 2004).

Já em relação ao tamanho do município de Iguape, este teve seu território reduzido em cerca de 400 ha, com a alteração cartográfica devido à abertura do canal-do-furado. O limite municipal entre Iguape e Peruíbe, que era o curso natural do rio Comprido, passou a ser registrado nos mapas oficiais como sendo através do canal artificial aberto no passado.

Apesar das consequências ambientais e geográficas causadas pela abertura do canal-do-furado, que originou a Ilha do Ameixal e inviabilizou a navegação de embarcações de maior porte no rio Una do Prelado ou Comprido e impediu o desenvolvimento regional, devemos considerar que, de certo modo, tal intervenção favoreceu a criação da Estação Ecológica Juréia-Itatins, pois, caso não tivesse ocorrido e esta região continuasse a se desenvolver, as propriedades ao longo deste curso d'água poderiam continuar a produzir e escoar sua produção, poderiam em função da demanda ampliar suas áreas de produção em detrimento da conservação ambiental.

\section{CONCLUSÕES}

Toda alteração no curso natural de rios e outros cursos d'água devem ser antecipadamente estudadas, para que as consequências ambientais não venham a inviabilizar os empreendimentos propostos, as atividades econômicas e até mesmo a navegação, que pode ser dificultada ou totalmente impossibilitada, conforme se pode verificar tanto no Valo Grande quanto no canal-do-furado do rio Comprido, ambos no município de Iguape.

Além disso, conclui-se que estudos dessa natureza são importantes para evitar equívocos que o desconhecimento do histórico de uso dos locais pode causar, tais como a sinalização incorreta do limite de município entre Iguape e Peruíbe, cujo limite original é o rio Comprido, assim como a criação de uma Área de Relevante Interesse Ecológico em uma ilha artificial, criada por intervenções antrópicas sofridas no passado.

Considerou-se que a criação da ARIE da Ilha do Ameixal, em 1985, foi uma atitude louvável de seus idealizadores, inclusive na época em que ocorreu. Porém, mesmo que ela não tivesse sido criada, no ano seguinte, ou seja, em 1986 foi criada a Estação Ecológica de Juréia-Itatins e o território da ARIE foi totalmente sobreposto pelo da Estação Ecológica, que é uma categoria de manejo ainda mais restritiva e, portanto, traria mais proteção do ponto de vista legal.

De certo modo tal intervenção efetuada no curso do rio Comprido favoreceu a criação da Estação Ecológica Juréia-Itatins, pois, caso não tivesse ocorrido e esta região se desenvolvesse, as propriedades ao longo deste curso d'água poderiam continuar a produzir e escoar sua produção em detrimento da conservação do meio ambiente, que deveria ser degradado pela ampliação das áreas de cultivo e extrativismo que existiam ao longo de toda a extensão do curso d'água. 


\section{REFERÊNCIAS BIBLIOGRÁFICAS}

BRASIL. Lei $n^{\circ}$ 6.938, de 31 de agosto de 1981. Dispõe sobre a Política Nacional do Meio Ambiente, seus fins e mecanismos de formulação e aplicação, e dá outras providências. Disponível em: $<$ http://www.planalto.gov.br/ccivil_03/leis/16938.htm>. Acesso em: 3 abr. 2015.

Decreto $\mathrm{n}^{\circ}$ 89.336, de 31 de janeiro de 1984. Dispõe sobre as Reservas Ecológicas e Áreas de Relevante Interesse Ecológico, e dá outras providências. Disponível em: <http://www2.camara.leg.br/ legin/fed/decret/1980-1987/decreto-89336-31-janeiro-1984-439049-publicacaooriginal-1-pe.html>. Acesso em: 3 abr. 2015.

Decreto $\mathrm{n}^{\mathrm{o}}$ 91.889, de 5 de novembro de 1985. Declara como Área de Relevante Interesse Ecológico - ARIE a Ilha denominada Ameixal, situada no Rio Una, no Estado de São Paulo, e dá outras providências. Disponível em: <http://www.icmbio.gov.br/cepsul/legislacao/decretos/382-1985.html>. Acesso em: 4 abr. 2015.

BRASIL. Ministério do Meio Ambiente - MMA. Sistema Nacional de Unidades de Conservação da Natureza - SNUC. Instituído pela Lei n. 9.985, de 18 de julho de 2000; Decreto $\mathrm{n}^{\circ} 4.340$, de 22 de agosto de 2002. 5. ed. Brasília, DF: MMA/SBF, 2004. 56 p.

COMMISSÃO GEOGRAPHICA E GEOLOGICA DO ESTADO DE SÃO PAULO - CGG. Exploração do Littoral - cidade de Santos á fronteira do Estado do Paraná. São Paulo: Typographia Brazil de Rothschild \& Co., 1920.40 p.

GEOBRÁS/S.A. ENGENHARIA E FUNDAÇÕES. Complexo Valo Grande - Mar Pequeno Ribeira de Iguape. Itapecerica da Serra, 1966. v. 1, 448 p. (Relatório apresentado à Secretaria dos Serviços e Obras Públicas Departamento de Águas e Energia Elétrica - Serviço do Vale do Ribeira).

HOUAISS, A.; VILLAR, M.S.; FRANCO, F.M.M. (Ed.). Dicionário eletrônico Houaiss da Língua Portuguesa. Versão 1.0.5a. Rio de Janeiro: Objetivo, 2002. (CD-ROM).

INSTITUTO BRASILEIRO DE GEOGRAFIA E ESTATÍSTICA - IBGE. Divisão administrativa. 2010. Disponível em: <http://www.ibge.gov.br>. Acesso em: 10 set. 2014.

Cidades@: Iguape. 2014a. Disponível em: <http://www.cidades.ibge.gov.br/xtras/perfil.php? lang $=\&$ codmun $=352030 \&$ search $=\mid$ infogr\%E1ficos:-informa\%E7\%F5es-completas $>$. Acesso em: 7 set. 2014.

Cidades@: Iguape - Índice de Desenvolvimento Humano Municipal (IDHm) - 2010. 2014b. Disponível em: <http:/www.cidades.ibge.gov.br/cartograma/mapa.php?lang=\&coduf=35\&codmun=352030\& idtema $=16 \& \operatorname{codv}=\mathrm{v} 20 \&$ search=sao-paulo|iguape|sintese-das-informacoes->. Acesso em: 4 abr. 2015.

Cidades@: Iguape - Histórico. 2014c. Disponível em: <http://www.cidades.ibge.gov.br/painel/ historico.php?lang=\&codmun=352030\&search=sao-paulo|iguape|infograficos:-historico $>$. Acesso em: 6 set. 2014.

Cidades@: Peruíbe. 2014d. Disponível em: <http://www.cidades.ibge.gov.br/xtras/perfil.php? $\overline{\text { lang }=\&}$ codmun $=353760 \&$ search $=$ sao-paulo|peruibe $>$. Acesso em: 7 set. 2014.

INSTITUTO DO PATRIMÔNIO HISTÓRICO E ARTÍSTICO NACIONAL - IPHAM. Patrimônio cultural: Iguape. Disponível em: <http://www.portal.iphan.gov.br/portal/montarPaginaSecao.do;jsessionid= C8A07C68C0AB14EAB447EEA1E7BCAEF1?id=18114\&retorno=paginalphan>. Acesso em: 4 abr. 2015.

MENEZES, M.P. A influência da ação antrópica na dinâmica sedimentar costeira: estudo de casos na Estação Ecológica de Juréia-Itatins - SP. 1994. 110 f. Dissertação (Mestrado em Ciência Ambiental) Programa de Pós-Graduação em Ciência Ambiental - PROCAM, Universidade de São Paulo, São Paulo.

NOGUEIRA-NETO, P. Breve História da área da Juréia-Itatins como Unidade de Conservação. In: MARQUES, O.A.V.; DULEBA, W. (Ed.). Estação Ecológica de Juréia-Itatins: ambiente físico, flora e fauna. Ribeirão Preto: Holos, 2004. cap. 1, p. 13-15. 
MOURA, C. et al. Consequências da alteração no curso do rio Comprido, Iguape, SP.

POR, F.D. Hidrobiologia da Juréia e da Baixada do Ribeira - rios e manguezais. In: MARQUES, O.A.V.; DULEBA, W. (Ed.). Estação Ecológica de Juréia-Itatins: ambiente físico, flora e fauna. Ribeirão Preto: Holos, 2004. cap. 5, p. 51-57.

SÃO PAULO (Estado). Decreto Estadual $\mathrm{n}^{\circ}$ 24.646, de 20 de janeiro de 1986. Cria a Estação Ecológica de Juréia-Itatins e dá outras providências. Diário Oficial do Estado de São Paulo, v. 96, n. 014, 21 jan. 1986. Disponível em: <http://www.ibama2.ibama.gov.br/cnia2/renima/cnia/ lema/lema_texto/HTM-ANTIGOS/ 24646-86.HTM>. Acesso em 20 dez. 2010.

. Lei $\mathrm{n}^{\mathrm{o}}$ 14.982, de 8 de Abril de 2013. Altera os limites da Estação Ecológica da Jureia-Itatins na forma que especifica, e dá outras providências. São Paulo: Assembleia Legislativa do Estado de São Paulo. Disponível em: <http://www.al.sp.gov.br/repositorio/legislacao/lei/2013/lei-14982-08.04.2013.html>. Acesso em: 4 abr. 2014.

SOUZA, C.R.G.; SOUZA, A.P. Geologia e geomorfologia da área da Estação Ecológica Juréia-Itatins. In: MARQUES, O.A.V.; DULEBA, W. (Ed.). Estação Ecológica de Juréia-Itatins: ambiente físico, flora e fauna. Ribeirão Preto: Holos, 2004. cap. 2, p. 16-33.

SUGUIO, K. O papel das variações do nível relativo do mar durante o Quaternário tardio na origem da baixada litorânea de Juréia, SP. In: MARQUES, O.A.V.; DULEBA, W. (Ed.). Estação Ecológica de Juréia-Itatins: ambiente físico, flora e fauna. Ribeirão Preto: Holos. 2004. cap. 3, p. 34-41.

VALENTIN, A. Comércio marítimo de abastecimento: o Porto de Iguape (SP), 1798-1880. In: CONGRESSO BRASILEIRO DE HISTÓRIA ECONÔMICA, 5., 2003. Caxambu. Anais... Caxambu: ABPHE. Disponível em: <http://www.registro.unesp.br/sites/museu/basededados/ arquivos/00000313.pdf>. Acesso em: 15 jun. 2010. 